\title{
Environmental benefits of modern power system and clean energy
}

\author{
Vedaste Ndayishimiye ${ }^{1, *}$, Xu Zhang $^{1}$, Deborah Nibagwire ${ }^{1}$, Patrobers Simiyu ${ }^{1}$, Giovanni Dushimimana ${ }^{2}$, Sefu $^{\text {Bikorimana }}{ }^{2}$ \\ ${ }^{1}$ Department of Electrical and Electronic Engineering, North China Electric Power University, Beijing 102206, China \\ ${ }^{2}$ Environmental Engineering, Zhejiang Normal University, Zhejiang Sheng 321001, China
}

\begin{abstract}
Nowadays, the world is at a critical moment of facing serious environmental and economic problems. A very large number of people in developing countries is exposed to dangers associated with flammability and toxicity of traditional source of energy while others in industrialized countries are facing the effects of atmospheric air pollution and green house (GHG) gas emission .Despite the global reforestation policies, despite latest remarkable increase in renewable energy and natural gas production, there is still a problem of domination fuel and coal consumption. This paper explored the effects of rapid economic growth, industrial development on climate. Additionally the effects of continuous exponential population growth, a fast increase of energy global energy demand, conventional transport system on carbon and GHG emission have discussed. Finally the paper revealed how modern smart electricity system with sustainable energy system and electric transport system contribute to the reduction of hazardous emission.
\end{abstract}

\section{Introduction}

Our society is presently at a critical moment of facing serious environmental, social, and economic problems. The diminution of carbon emission at the same time keeping a rapid economy development is a big challenge for developing nations. These days almost the entire transport system is depending on oil-derived fuel and internal combustion engine. The current is to develop a common understanding that is both beneficial to the enormous majority of human race and ecologically sustainable. However, now there is hope that a right decision that can lead to a healthy and clean future can be taken [1]. That is, to develop a stable and efficient energy, environmental and transport system to meet the demands of modern economic systems and living conditions [2][3].

In many developing countries a large section of the population are exposed to dangers associated with the sources of energy that they use like kerosene, charcoal, biomass and wood fuel. The flammability and toxicity of gases released by these energy sources coupled with the poor ventilation of their houses is a hazardous risk for these people. Fire accidents and other grave respiratory health problems are common phenomena in these parts of the world. On the other hand, industrialized countries produce high levels of atmospheric air pollution and greenhouse gas (GHG) emission. Their cities are characterized by streets jammed with cars, high number of factories, fossil fuel based power plants, home heating and cooling systems. Since most of these activities are power by coal and fuel, they contribute significantly to air pollution and GHG emission [4].
The air pollution is mainly a result of a large number of people using wood fuels and burning forests to pave way for agriculture lands especially in In north-west of Africa. Another region with high concentration of air pollution is the south of Asia where key contributors include fuel combustion for home cooking and heating, coal combustion for electricity generation, burning of forests for agriculture, oil based industrial and transport sectors [5]. In $2016,33.7 \%$ of global population or 2.45 billions ( 1 in 3 ) were exposed to the household air pollution effects. $90 \%$ of people in Africa are exposed to household air pollution due to the solid fuel combustion. $43 \%$ of people in China (which is 506 million) and 30\% of people in India (416 million ) use solid fuel [5].

There are evidences indicating a gradual increase of GHG emission despite the fact that many countries are planting forests, investing in wind, solar and other renewable energy sources. This can be attributed to the rapid population growth and industrialization in developing countries. The main challenge of minimizing the use of fossil fuels, is to regulate overpopulation while simultaneously regulating the over-utilization of nonrenewable energy resources. Therefore the construction of coal plants have been increasing exponentially due to its easy burning process in electricity generation and low price compared to oil and natural gases [6]. This is why United State, China and India and other industrialized countries depend of coal based electric power plants [7]. The global population and economy growth, industrial development and several urbanization projects in developing countries result in a significant increase of world energy demand. Energy use in developing 
countries is influenced by the growth in urbanization facilities along with industrial development [8].

The electric vehicle (EV) was proposed to be as a solution for aiding in reduction of carbon emission from conventional internal combustion engine (ICE). So the best way of analysing the impacts of EV in climate change is to take into account the means of electricity generation, consider fuel extraction's carbon emission, source of electric energy used in EV manufacturing and power loss compensation in power lines. Consequently EVs operating on a coal dominated power generation can produce enormous amounts of carbon emission because EVs are not standalone technology to cut down carbon emission. However, they need a green electricity production to achieve an efficient green transportation mode[9].

To get reliable information, the statistical data used in this paper concerning the state of the art on global energy demand and production have been taken from BP Energy outlook report 2018 edition, WWF REPORT UK March 2011, Electrical Power Research Institute (EPRI), World Wide Fund (WWF) report 2011, and Shrink That Footprint February 2013. The proposed solution was taken based on the updated research findings of IEEE Transactions on Transportation and Electrification, IEEE Transactions on Intelligent Transportation Systems and IEEE Transactions on Smart Grid.

\section{Statistical review of global electricity demand, generation and consumption}

At the first sight there is a significant increase in energy demand in general. For the first time in 4 years the coal consumption has increased. This has affected the growth in carbon emission which was almost showed no growth in three successive years.

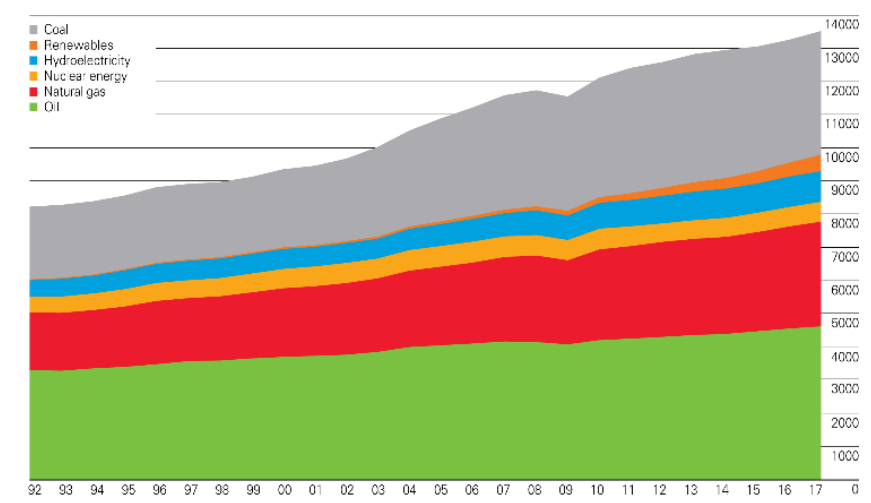

Fig. 1. Primary energy world consumption(Million tonnes oil equivalent) [10].

From 2016, the primary energy consumption increased $1.2 \%$ and $2.2 \%$ in 2017 . It can be seen in Fig. 1 and Fig. 3 that all fuels excluding coal in addition to hydro-power increased considerably. Fossil fuel renewable energy have played a significant role in energy use growth apart from coal based electricity generation [10].

\subsection{Renewables, hydro and nuclear}

Considering the sector demand, as shown in Fig. 2, the industrial sector uses around 50\%, residential and commercial building use $29 \%$ while transport sector consumes $20 \%$ of the global energy. Without any doubt, as the global population increases, the more energy demand in residential buildings increase correspondingly to supply electrical appliances, lighting and heating systems. This growth of energy demand is slightly slow in transport sector due to the current development of electric vehicle technology[8].

Despite the increment of electricity and natural gas in transportation and other alternative fuels, there is still a problem of domination of oil in every single mode of transportation as indicated in Fig. 2, Fig. 3 and Fig. 4. The highest partition of fuel demand in transportation comes from developing countries[8].

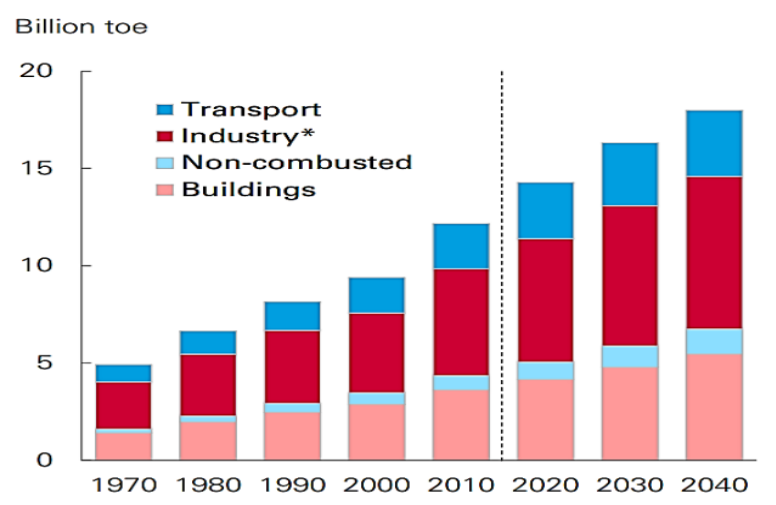

Fig. 2. Primary energy consumption by end use sector.

\subsection{Power sector}

In in 2017 the total power generation rose by $2.8 \%$. The growths of renewable energy production, particularly wind and solar energy, only contributed over a half of total generation. For instance solar capacity generated in China in 2017 was $50 \mathrm{GW}$ which is a half of the total production of global solar energy generation. The scariest and worrying fact is that for the last 20 years the power sector depended much on fuel mix. The reduction of fuel mix in power sector is still unproductive over the last 20 years from 1997 as shown in Fig. 3. This happens despite the will of shifting away from coal consumption into cleaner energy and low carbon fuels, despite latest remarkable increase in renewable energy production. The portion of coal used in electricity production in 1997was $38 \%$ which is just the same as that used in 2017 [10]. (Table 1). 
Table 1. Global Coal Consumption and its prediction until 2040 [10].

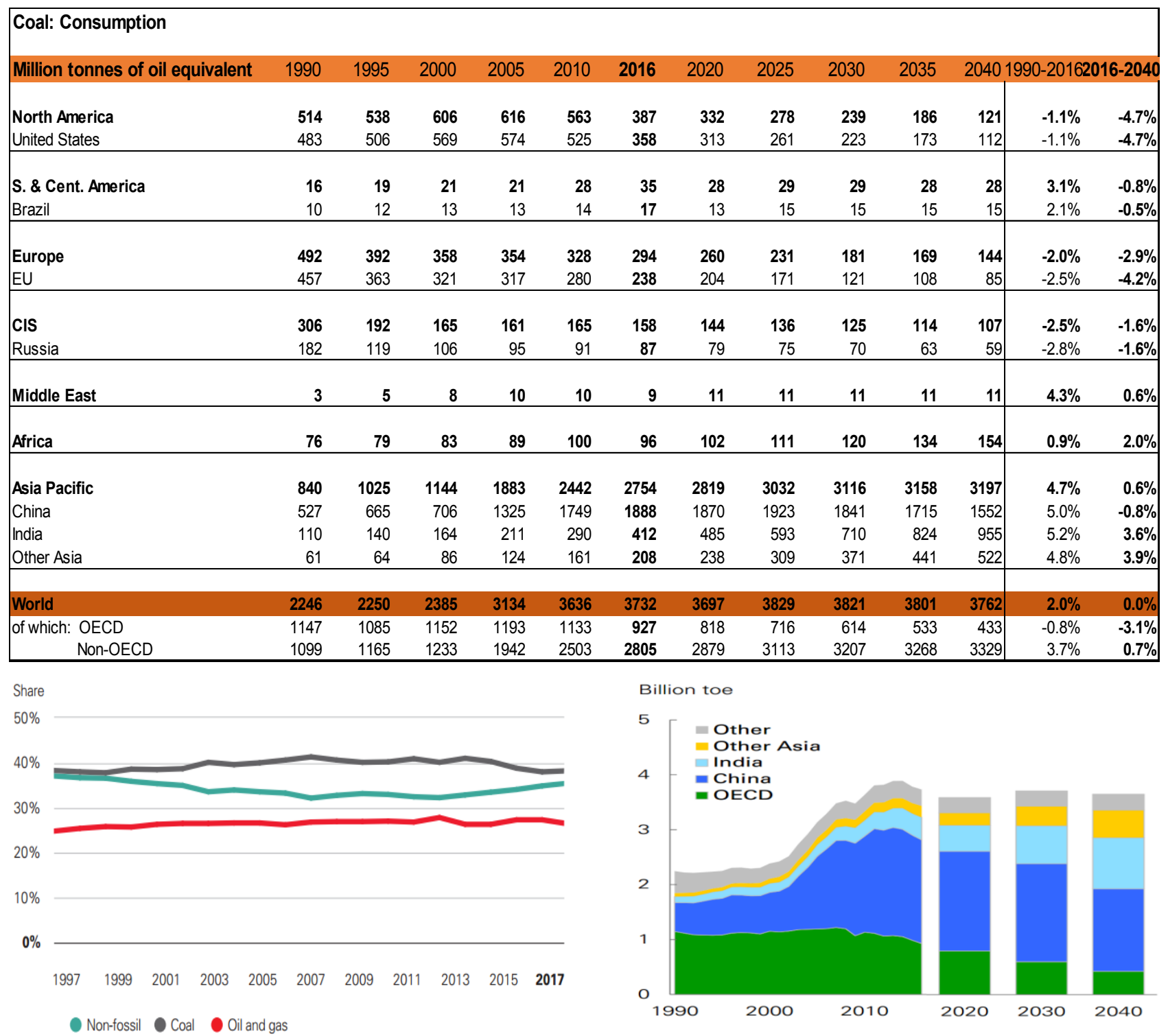

Fig. 3. Fuel shares in power generation[10].

Fig. 5. Coal consumption by region oal consumption by region[10].

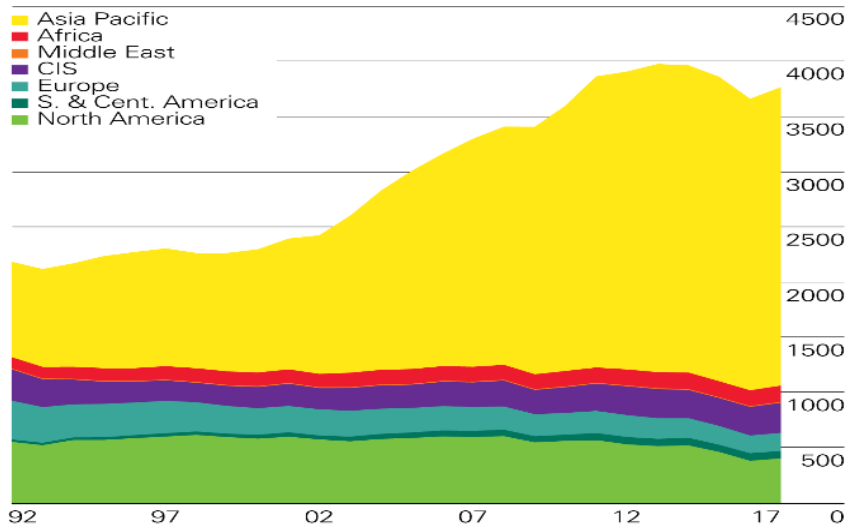

The global power demand is still dominated by coal with $38.1 \%$ as the primary energy. This is approximately the total of natural which has $23.2 \%$ and hydroelectricity of $15.9 \%$ together. Since 2007 until 2017 the renewable power generation has increased from $6.1 \%$ to $8.4 \%$ while nuclear and coal decreased by $3.4 \%$ and $3.1 \%$.

As shown in Fig. 5 there is a slow decrease in coal demand in OECD and China. On the other hand a considerable increase of coal demand is obtained in developing countries with a rapid industrialization which need continuous and sufficient electricity. India has a significant increase of coal demand followed by Asian nations with fast economy growth[11].

Fig. 4. Coal production. 


\section{Smart Grid for green future}

\subsection{Green grid}

A smart grid alone does three things. First, it modernizes power systems through self-healing designs, automation, remote monitoring and control, and establishment of microgrids. Second, it informs and educates consumers about their energy usage, costs and alternative options, to enable them to make decisions autonomously about how and when to use electricity and fuels. Third, it provides safe, secure and reliable integration of distributed and renewable energy resources. All these add up to an energy infrastructure that is more reliable, more sustainable and more resilient. Thus, a smart grid sits at the heart of the smart city, which cannot fully exist without it[12].The integration of small scale distributed generations units for example PV generation plants and wind power plant in addition to the efficient supply of electric vehicle, Plug-in Hybrid Electric Vehicle PHEV is the solution to the challenges of modern power system [13].

Currently the electricity price is changing as a function of electricity demand along with supply conditions on the basis of capacity, fuel capacity, weather aspects and power demand variation as time goes on. (i)Demand side management (DMS) technology uses alert signal sent autonomously by the utility company to notify a customer for turning down unnecessary appliances which can increase the electricity price during the peak hours. This eliminates the need for dispatching an addition power generation unit hence reducing carbon emission. (ii) Smart grid let the consumers track their energy consumption and offers required updated information of electricity pricing which allows the client to select a desired electricity provider in accordance with carbon emission besides facilitating load shifting and load shedding (iii) Smart grid avoids the need for running additional generators during a peak demand and provides energy management services to the customers to remotely manage home energy system. It allows electricity company to make "SAVE-A-WATT" program which replaces the need of producing $1 \mathrm{kwh}$ of electricity (iv) $\mathrm{SG}$ increases renewable energy generation in home, campus, buildings and factories with less carbon emission. This reduces the peak demand of the utility grid thus decreasing the demand of new addition fuel power plants[14].

In Smart grid the smart meters technology along with indirect feedback, temporary/permanent peak load reduction and other intelligent load control schemes lead to an efficient power savings through peak demand reduction and avoid unnecessary operation of additional Peaker plants [15]. Customer can choose to use a green energy selected from the utility grid or own a small generation unit such as rooftop solar PV system connected to the grid. By saving $1 \mathrm{KWh}$ of electric energy, some quantity of fossil fuel and coal is saved from burning in power plants hence GHG emission and other related air pollutants are reduced.

\subsection{Green transportation}

Some of the main challenges of the current transportation system are the fast decrease of fossil fuels, environmental related problems, global population growth requiring high level of living standards and the needs of personal transport facilities[11]. Besides, most of transport sector of developing countries are still operating under the old technology with high energy demand and carbon emission[16][11]. From the perspective of the electricity industry, EV consumption will result in increased demand along with an increase in absolute $\mathrm{CO} 2$ emissions associated with electricity generation.

Road transport is a leading sources of urban and local gaseous air pollutants, climate change, acidification, suspended particle matter (PM), nitrogen dioxide and black smoke in area of high traffic concentration. The black carbon is produced by incomplete combustion process in diesel engine of a vehicle and its quantity depends on efficiency of combustion, exhaust treatment and amount of used fuel[17].

The only way forward for the increasing world population with its rising demand for public and individual mobility is to develop an affordable efficient and reliable renewable energy system. This should be integrated into the existing power utility to mitigate the carbon emission and boost the system efficiency while lowering the operating cost by replacing ordinary fossil fuel with renewable energy. The conventional wasteful energy logistics, i.e. fuel distribution by road, rail, waterways and pipelines will be substituted by the elegant and pollution free electric grids which will be "smarter", i.e. adapt to the loads intelligently with hydraulic and buffer storage by millions of vehicle batteries. Therefore in smart transportation concepts or clean transportation, the vehicles have to be non-pollutant or electric vehicles operating via smart grid[11].

Electric vehicles (EVs) and solar photovoltaics (PV) are highly promising new technologies and are widely expected to play a major role in the electricity industry in the coming decades. EVs are emerging as a potentially significant element of the future transport to solve the problems of oil availability and pricing, as well as growing concerns over climate change. On the supply side, solar PV has been one of the fastest growing renewable technologies worldwide over the past decade due to its potential contribution toward addressing security of electricity supply and environmental challenges. With its falling costs, PV deployment seems certain to continue growing rapidly[18] [19].

The key advantage of $\mathrm{EV}$ is its involvement in decarbonisation of the traditional road transportation system. In addition, they help decrease of global oil dependence through replacement of existing petrol or diesel vehicles with electric vehicles, bikes and trains[20]. However EVs operating on a coal dominated power generation can produce enormous amounts of carbon emission. For instance, electricity generation produces almost $25 \%$ of the global GHG emissions[14]. Therefore, EVs are not standalone technology to cut down carbon emission. Hence the best way of analysing the impacts of $\mathrm{EV}$ in climate change is to take into account the means of 
electricity generation, carbon emission arising from fuel extraction, source of electric energy used in EV manufacturing and power loss compensation in power lines[9]. To achieve the objectives of the EV technology, it is necessary that the utility grid uses renewable energy to speed up the elimination of carbon emission [4. However, they need a green electricity production with new technology and adoption of Smart Grids to achieve an efficient green transportation mode[9] [14]. We believe that minimizing and even elimination of the share of GHGs emissions arising from the transportation and the power generation sectors will be possible in the long run by further utilizing renewables, electro mobility and proper DDR techniques. Besides, the emissions from power generators could be reduced in smart grids wherein there is high penetration of renewables and distributed generation (DG)[21].

The smart grid use energy storage technology to deal with intermittency characteristics of renewable energy sources thus providing an efficient EV power demand and maximizing the utilization of renewable energy resources. This feature of $\mathrm{SG}$ provides the sustainable environment[13]. Hence the massive utilization of EVs based on renewable energy smart grid in our regular transportation can eliminate fuel and oil dependence in transportation sector, reduce carbon emission and local air pollution while developing the renewable energy application, [20][19][9].

To sum-up, the smart grid has several benefits for the environment which can be realized by integration and interconnection of renewable energy resources, for instance, solar energy, solar thermal energy, wind, geothermal and biofuel energy in the utility grid. The energy system based on renewable resources can reduce the existing rapid depletion of non-renewable resources hence enhance sustainability. The application of smart devices such as smart metering and smart appliances in smart homes also will decrease energy losses. Therefore, combining all discussed advantages and services provided by the smart grid, there is no doubt that it is able to reduce emission of GHG and carbon as well as other air contaminant thereby improving air quality.

\section{References}

1. R. Costanza and I. Kubiszewski, Creating a Sustainable and Desirable Future. 2014.

2. M. C. Falvo, R. Lamedica, R. Bartoni, and G. Maranzano, "Energy management in metro-transit systems: An innovative proposal toward an integrated and sustainable urban mobility system including plug-in electric vehicles," Electr. Power Syst. Res., vol. 81, no. 12, pp. 2127-2138, 2011.

3. M. C. Falvo and F. Foiadelli, "Preliminary analysis for the design of an energy-efficient and environmental sustainable integrated mobility system," IEEE PES Gen. Meet. PES 2010, pp. 1-7, 2010 .
4. J. E. Hardoy and D. Satterthwaite, "Environmental Problems in Third World Cities: A Global Issue Ignored?," 'Cities - Mainspring Econ. Dev. Dev. Ctries., no. August, 1989.

5. H. E. Institute, "State of Global Air 2017. Special," 2017.

6. Abbas Ghassemi, Energy and the Environment. CRC Press, 2011.

7. W. Sweet, "Kicking the Carbon Habit: Global Warming and the Case for Renewable and Nuclear Energy," Columbia.University.Press, no. Apr, p. 268, 2006.

8. BP Energy Economics, "2018 BP Energy Outlook 2018 BP Energy Outlook,” 2018 BP Energy Outlook, p. $125,2018$.

9. L. Wilson, "Shades of Green: Electric Cars' Carbon Emissions Around the Globe," Shrink that Footpr., vol. 91, p. 29, 2013.

10. BP, " 67 th edition Contents is one of the most widely respected," Stat. Rev. World Energy, pp. 1-56, 2018.

11. G. R. Grob, "Future Transportation with smart grids \& sustainable energy," Int. J. COMADEM, vol. 13, no. 4, pp. 2-7, 2010.

12. K. Geisler, "The Relationship Between Smart Grids and Smart Cities," IEEE SmartGrid Newsl. Compend., vol. 5, pp. 1-3, 2015.

13. M. C. Falvo, L. Martirano, D. Sbordone, and E. Bocci, "Technologies for smart grids: A brief review," 12th Int. Conf. Environ. Electr. Eng. EEEIC 2013, pp. 369-375, 2013.

14. W. Frye, "Smart Grid The Role of Electricity Infrastructure in Reducing Greenhouse Gas Emissions," CISCO-White Pap., no. October, 2008.

15. EPRI, "The Green Grid: Energy Savings and Carbon Emissions Reductions Enabled by a Smart Grid," Electr. Power Res. Inst., vol. 3, no. 3, p. 64, 2008.

16. B. $\mathrm{Xu}$ and B. Lin, "Carbon dioxide emissions reduction in China's transport sector: A dynamic VAR (vector autoregression) approach," Energy, vol. 83, pp. 486-495, 2015.

17. R. N. Colvile, E. J. Hutchinson, J. S. Mindell, and R. F. Warren, "Millennial review: The transport sector as a source of air pollution," Atmos. Environ., vol. 35, pp. 1537-1565, 2001.

18. P. Vithayasrichareon, G. Mills, and I. F. Macgill, "Impact of electric vehicles and solar pv on future generation portfolio investment," IEEE Trans. Sustain. Energy, vol. 6, no. 3, pp. 899-908, 2015.

19. C. Clark and C. C. Group, "Environmental Benefits of Plug-In Hybrid Electric Vehicles," pp. 1-6, 2006.

20. S. C. Change, "Electric avenues anD initiaLS," no. March, 2011.

21. F. Rassaei, W.-S. Soh, and K.-C. Chua, "Decarbonized Demand Response for Residential Plug-in Electric Vehicles in Smart Grids," no. Ldv, 2016. 